\title{
Study of the possibilities to achieve an energy mix in areas affected by restructuring of lignite exploitation
}

\author{
Danut Grecea ${ }^{1, *}$, Marin Silviu Nan $^{2}$, Cristian Aron ${ }^{2}$, Cosmin Vitan ${ }^{2}$, and Bogdan Tomus ${ }^{2}$ \\ ${ }^{1}$ National Institute for Research and Development in Mine Safety and Protection to Explosion - \\ INSEMEX, 32-34 G-ral Vasile Milea Street, Petrosani, Romania \\ ${ }^{2}$ University of Petrosani, 20 University street, 332006, Petrosani, Romania
}

\begin{abstract}
The general topic of this paper is to study the possibilities of using renewable energy sources to supply urban consumers electricity, consumers located in areas affected by industrial restructuring. This carries out a comprehensive study on the possibilities of using renewable energy sources in the Motru Basin area. Moreover, creation a mix capable of producing the electricity needed by the inhabitants, in household consumption and not only, is being studied. The entry of free energy market has brought about the alignment with competitive conditions and observance of pollution regulations in force, and energy production has determined retrofitting or restriction of the activity of some thermal power plants due to non-competitive costs for primary energy resources. Our country has a diversified and balanced energy mix (hydropower, nuclear energy, coal and natural gas) but it must be complemented by renewable sources (wind, solar, biomass) to provide stability and energy safety prospects.
\end{abstract}

\section{Introduction}

Electricity consumption has led to both an increase in pollution levels and a decrease in fossil fuel sources, and in this direction one of the priority policies of energy stability in the EU, implicitly also in Romania is energy efficiency and increased renewable energy generation.

Following the EU's accession to the Paris Agreement and with the publication of the Energy Union Strategy, the EU has taken an important role in combating climate change through its five main dimensions: energy security, decarbonisation, energy efficiency, the internal energy market and research, innovation and competitiveness. Thus, the European Union is committed to leading the global energy transition by meeting the intended objectives aimed at providing clean energy throughout the European Union [1].

Consequently, in order to ensure the achievement of these objectives, each Member State was obliged to submit to the European Commission a draft of the National Integrated

* Corresponding author: danut.grecea@insemex.ro 
Energy and Climate Change Plan (NIPIESC) for the period 2021-2030, projects setting out the national objectives and contributions to the achievement of the objectives [2].

Romania aims to make a fair contribution to achievement of European Union's decarbonisation target and will follow best practices for environmental protection by applying strategies and meeting annual emission targets, Romania's overall emission reduction target stands at around $44 \%$ by 2030 compared to 2005 , Figure 1 .

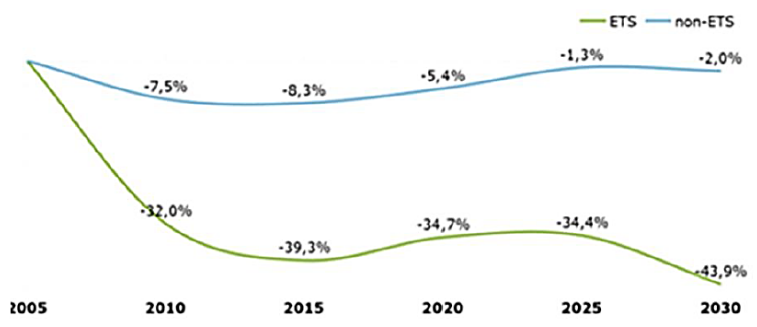

Fig. 1. Evolution and forecasting of emissions from the ETS (Emissions Trading System) and nonETS sectors compared to 2005.

The situation of energy production in the EU between 1990 and 2019 is summarised in the Figure 2 and recorded in the reports of the Council of Europe [1]. The downward share of energy produced from solid fuels and the constant increase in renewable energy production are observed.

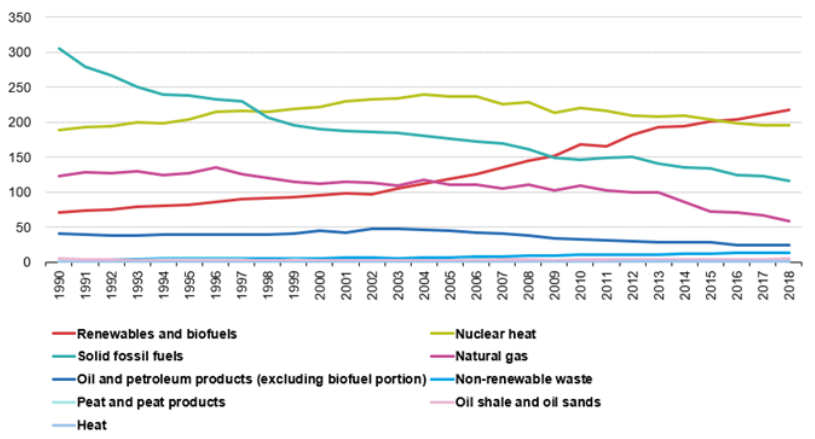

Fig. 2. Primary energy production by fuel, EU-27, in selected years, 1990-2018 (million tonnes of oil equivalent).

This trend, the availability of existing European funds, continuous expansion and competition in a liberalised market, and the need to maintain a stability of the electricity system have led to increased efficiency, with the standards imposed forcing design operators and network operators, to find sustainable solutions to use renewable energy sources. Entry into the free energy market required alignment with the competitive conditions and compliance with the pollution regulations in force. Thus, the policies on the profitability, reorganisation and efficiency of the energy production units have led to the retrofitting or restriction of the activity of such plants due to the competitive costs for primary energy resources, but also in this situation, our country continues to contain a diversified and balanced mix.

This paper is a study on the possibilities of using renewable energy sources for the supply of urban consumers located in areas affected by industrial restructuring, customized for the Motru Basin area by creating an energy mix.

Analysis of the possibilities to achieving the proposed mix is based on the studies presented by M.S. Nan [3] and A. Sultan [4] (through the environmental data connected 
with help of meteorological station belonging to University of Petrosani) and taking into account major impact of social protection due to the restructuring of mining activities in analysed area. Thus, in the current study, it is proposed to include coal-based energy to reduce social and economic impact of the population, and the transition to clean energy to be made gradually while respecting the commitments made mix.

\section{Current state of electricity, heat production and consumption in Motru Municipality}

The municipality of Motru is located in the south-western part of Gorj County in Romania, at the dividing line between Mehedinti County and Gorj County. The municipality is located on route DN 67A, $44 \mathrm{~km}$ from Targu-Jiu and $42 \mathrm{~km}$ from Drobeta Turnu Severin [3].

The heating of premises and the production of domestic hot water are almost exclusively provided by a centralised system, through the municipal heating power plant, SC UATAA SA Motru, using coal from the Motru extraction basin; distribution is carried out through the heating and hot water network. The production of electricity / heat in urban areas from renewable sources is relatively low, almost non-existent.

UATAA SA Motru is located in the southern area of Motru Municipality. The turbine trains an electric generator with a power of $5.5 \mathrm{MW}$, which produces electricity at a voltage of $6.3 \mathrm{kV}$ and a power factor of 0.8 .

Table 1 shows the production of energy within the central heating system U.A.T.A.A. Motru, and in the table 2, electricity consumption for year 2018 is presented [5].

Table 1. U.A.T.A.A. Motru - Production of electricity and heat in 2018.

\begin{tabular}{|c|c|c|c|c|c|c|}
\hline \multirow{2}{*}{$\begin{array}{l}\text { Nr. } \\
\text { crt. }\end{array}$} & \multirow{2}{*}{ Year } & \multirow{2}{*}{ Month } & \multicolumn{2}{|c|}{ Thermal - MWh } & \multicolumn{2}{|c|}{ Electrical - MWh } \\
\hline & & & Production & Cons. Techn. & Production & Cons. Techn. \\
\hline 1. & \multirow{12}{*}{2018} & Ian & 19.031 & 4.5553. & 622 & 1.202 \\
\hline 2. & & Feb & 17.363 & 4.154 & 3.287 & 1.074 \\
\hline 3. & & Mar & 17.783 & 4.497 & 3.614 & 1.182 \\
\hline 4. & & Apr & 3.45 & 1.38 & 0 & 234 \\
\hline 5. & & Mai & 3.983 & 1.593 & 0 & 258 \\
\hline 6. & & Iun & 3.542 & 1.47 & 0 & 249 \\
\hline 7. & & Iul & 3.743 & 155 & 0 & 271 \\
\hline 8. & & Aug & 3.935 & 1.633 & 0 & 275 \\
\hline 9. & & Sept & 3.83 & 1.589 & 0 & 267 \\
\hline 10. & & Oct & 4.349 & 1.652 & 222 & 303 \\
\hline 11. & & Noi & 17.866 & 4.399 & 3.512 & 1.156 \\
\hline 12. & & Dec & 18.499 & 4.53 & 3.618 & 1.208 \\
\hline \multirow{2}{*}{\multicolumn{2}{|c|}{ TOTAL }} & MWh & 117.374 & 31.608 & 17.875 & 7.678 \\
\hline & & $\%$ & $78.80 \%$ & $21.20 \%$ & $70.00 \%$ & $30.00 \%$ \\
\hline
\end{tabular}


Table 2. Electricity consumed in 2018.

\begin{tabular}{|c|c|c|c|c|}
\hline \multirow{2}{*}{ Destination of consumption } & \multirow{2}{*}{ U.M. } & \multicolumn{2}{|c|}{ Type of consumer } & \multirow{2}{*}{ Total } \\
\cline { 3 - 4 } & & Household & Non-household & \\
\hline Population & MWh & 28506 & 3829 & 32335 \\
\hline $\begin{array}{c}\text { Tertiary sector (crèches, kindergartens, } \\
\text { schools, hospitals, other public buildings, } \\
\text { etc.) }\end{array}$ & MWh & - & 1148 & $\mathbf{1 1 4 8}$ \\
\hline Water supply & MWh & - & 601 & $\mathbf{6 0 1}$ \\
\hline Total consumption & MWh & $\mathbf{2 8 5 0 6}$ & $\mathbf{5 5 7 8}$ & $\mathbf{3 4 0 8 4}$ \\
\hline
\end{tabular}

Histograms of the thermal energy consumption of the population and economic agents are shown in Figure 3.

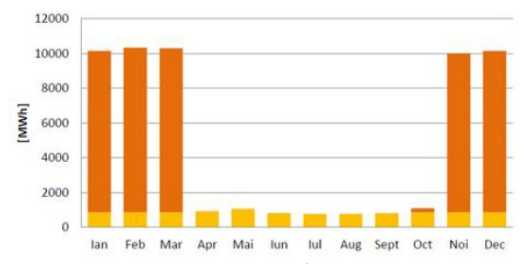

a)

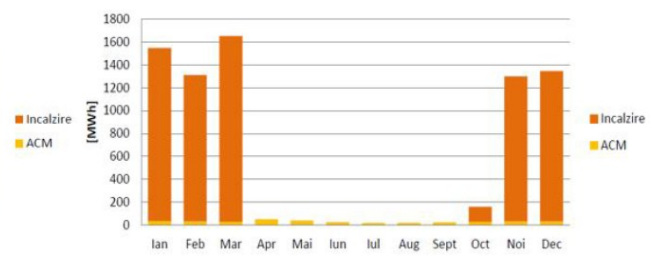

b)

Fig. 3. Thermal energy consumption of population and economic agents from UATAA Motru: a) consumption of thermal energy and domestic hot water (ACM) of population; b) consumption of thermal energy and domestic hot water (ACM) of economic agents.

\section{Study and assessment of renewable energy potential for Motru Basin area}

A systemic approach to the environment together with natural regenerative resources for the production of clean energy is achieved by analysing the positive influence, at local level of weather and climate phenomena, in order to stimulate the production of natural resources necessary to obtain clean energy. Building on knowledge of climate developments and using environmental management, the local climate can be influenced to generate primary energy resources for a sustainable renewable integrated energy system.

The study is carried out by two models, one for qualitative validation of the concept (using Petri networks) and one for quantitative validation (based on linear programming) for achieving maximum energy production. The first model provides the opportunity to better understand the natural cycle of water in nature and how it can be influenced, locally, so that we obtain water as a primary energy resource. The second model based on linear programming, allows to determine the dimensions of the surface in a heterogeneous area covered with a certain type of vegetation to produce maximum clean regenerative energy. Validation of the model is achieved by considering an area of $10 \mathrm{~km}^{2}$ of the Motru Basin area.

Expected results being that maximum energy can be achieved when using the sun, water and wind as renewable energy resources.

For an up-to-date picture of the current climate parameters, necessary in the analysis of the possibilities of modelling, simulation and analysis of the creation of a sustainable 
energy mix, the meteorological station belonging to the University of Petrosani is used [3 $5]$.

Following the analysis of the data collected from the Motru area, in the period 2017 2018, the parameters analysed are presented in Figures 4, 5 and 6.
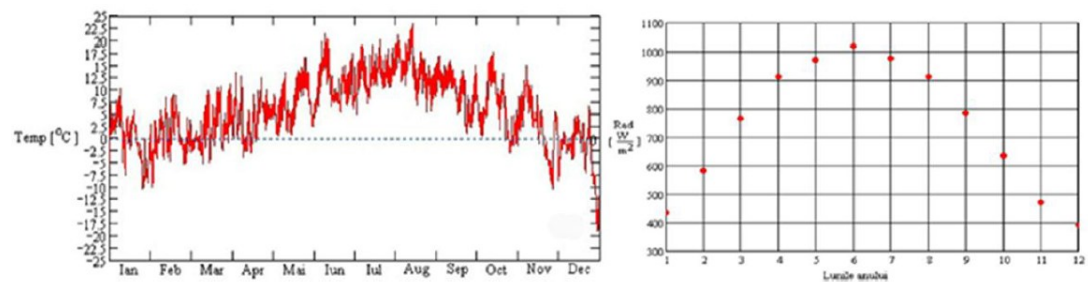

Fig. 4. Variation of temperature and solar radiation.
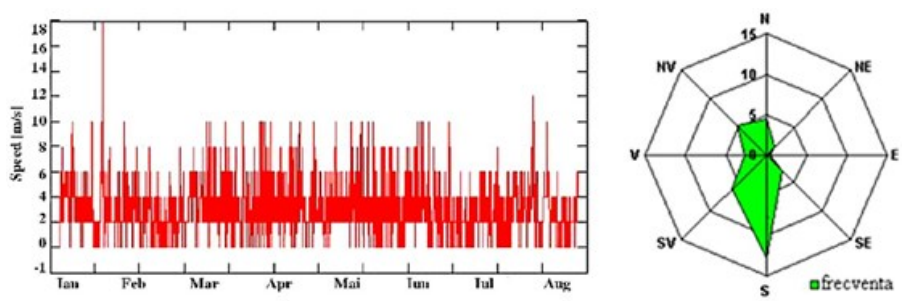

Fig. 5. Variation of wind speed during 2018 and frequency of wind beat.
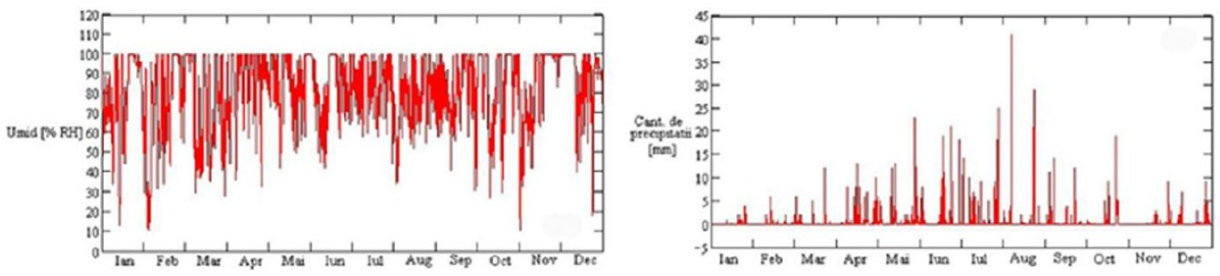

Fig. 6. Humidity variation and amount of precipitation.

Following the analysis of data collected from Motru Basin area, regarding the wind speed during 2018, it was observed that the average speed was about $4 \mathrm{~m} / \mathrm{s}$, in the south direction, Figure 5. The maximum wind speed, during 2018, was $18 \mathrm{~m} / \mathrm{s}$, being measured at the beginning of February.

Following the analysis of data, in Figure 6, the average humidity during 2018 was approximately $78.7 \% R H$, and variation in time of the amount by precipitation was uneven. Maximum amount of precipitation was reached at the end of July $(47 \mathrm{~mm})$.

\section{Simulation of energy produced by proposed energy mix for the Motru area}

Based on analysis for the presented aspects of Motru municipality, regarding aspect of providing electricity and heating agent, an energy mix is proposed that has integrated in its composition energy produced by the thermal power plant. This approach is supported by the need for a balanced transition (in terms of social impact) to clean energy production. The production of the needed energy from renewable sources for an area is the basis for sustainable development and at the same time ensuring energy security and increasing the quality of population life, in appropriate environmental conditions. 
For simulation, in MATLAB - Simulink [7, 8], model from Figure 7 was designed, where all particular parameters of the area were implemented, and components of each electricity generation element were exemplified and analysed as follows: for solar energy ( 8 MW photovoltaic plant), the modelling being presented in Nan, Grecea et al. Article [3], for wind energy (4.5 MW wind farm), the modelling being presented in Sultan, Nan et al. article [4], hydropower (10 MW micro hydropower plant using two 2 Francis turbines of 5 MW each), the modelling being presented in Amevi Acakpovi et al. article and article by E. Donaisky $[9,10]$. Components of model for simulation of energy production installation used are given below: wind energy, Figure 8; solar energy, Figure 9; micro hydropower plant, Figure 10 and thermal power plant, Figure 11.

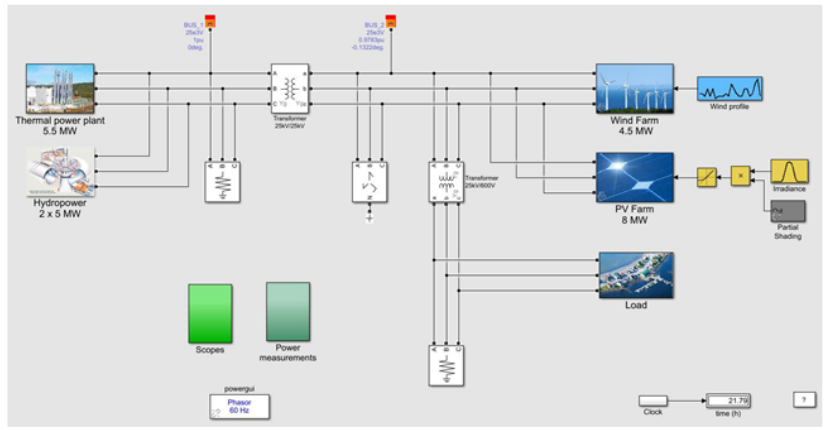

Fig. 7. Model simulation electricity generation mix.

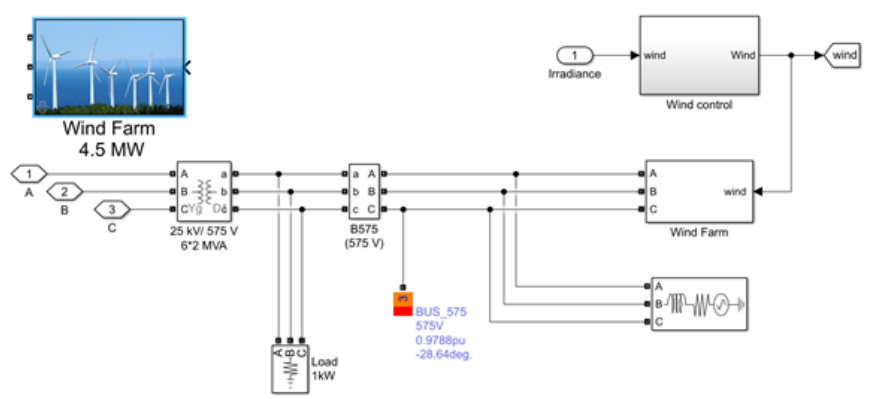

Fig. 8. Wind farm simulation model.

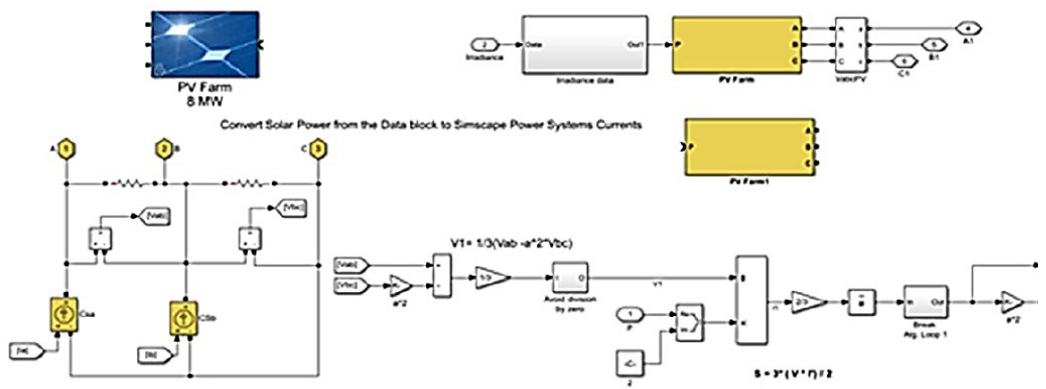

Fig. 9. Photovoltaic farm model simulation. 


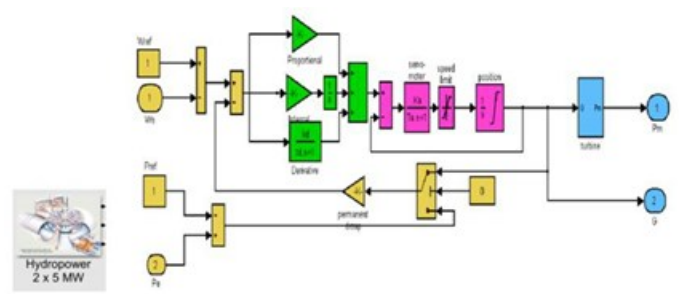

Fig. 10. Micro hydropower simulation model.

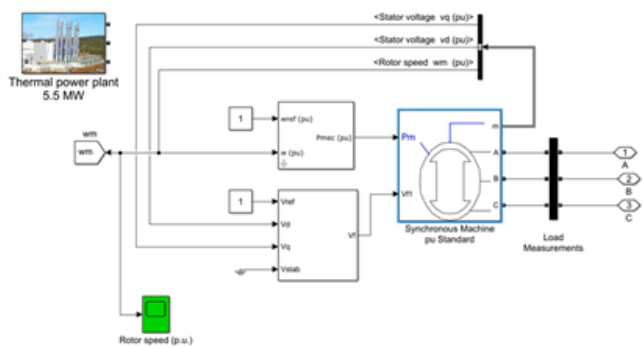

Fig. 11. Thermal power plant simulation model.

The results of simulation in measured meteorological conditions, using the most favourable conditions for 24 hours (solar energy, wind and maximum recorded water flow), are presented in figure 12 .

The simulation consists in production of energy using water, wind and solar radiation in maximum conditions.

In order to highlight the shortcomings of using only renewable energies, energy consumption was considered the average amount of energy consumed by population and economic agents, and energy produced by thermal power plant was ignored.

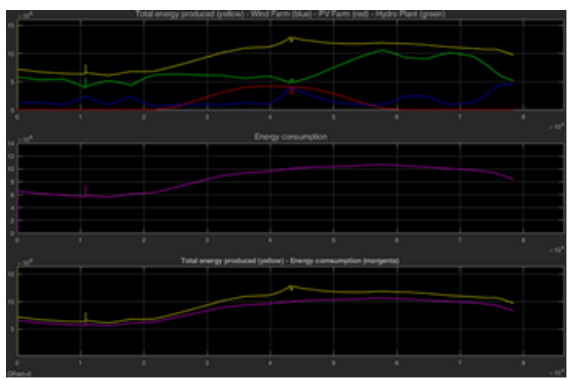

Fig. 12. Result of the simulation for the proposed energy mix.

From the graphs presented it is noted that the energy produced by the micro hydropower plant has the most significant weight. The energy produced by the wind is also variable, which is observed in Figure 13 being directly influenced by variations in wind speed. 

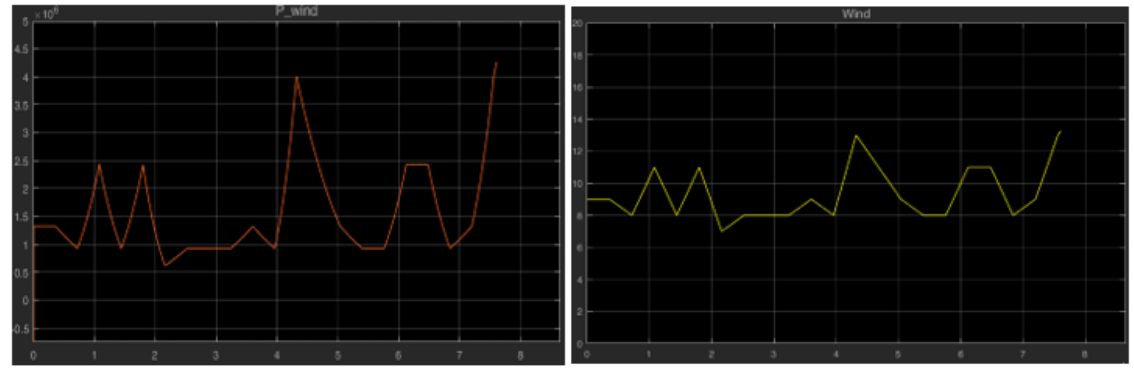

Fig. 13. Electricity resulting from simulation of the wind farm, energy produced (red) and variation of wind (yellow).

The energy produced by photovoltaic park is shown in Figure 14. This graph shows the shortcomings and limitations of using only this source to ensure sustainable energy security.

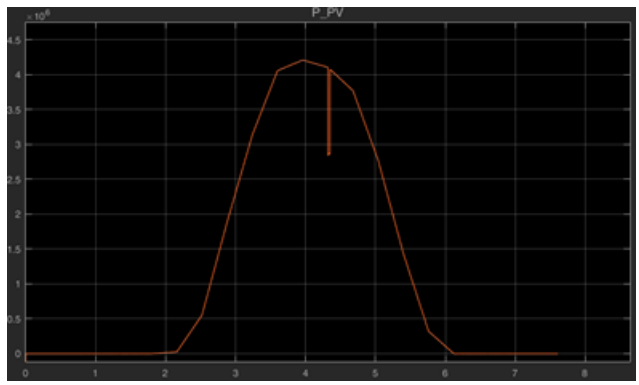

Fig. 14. Electricity resulting from simulation of photovoltaic park.

The result, based on real parameters used in simulations, highlights that the energy produced by analysed mix provides the necessary electricity for consumption and further validates proposed solution in which thermoelectric energy can be eliminated but for peak consumption situations, adverse weather conditions or extreme, thermal energy becomes the central element for configuration and capacity of proposed system.

\section{Conclusion}

Prolonged periods of drought, in particular, have increasingly highlighted the share of coal in electricity production. We must keep in mind that lignite and coal were the main resources that ensured the safe passage of winter period. Thus, in current conditions, reinforced by the particular aspects of a mono-industrialized area without viable solutions for various reasons (political, social protection), it proves once again that coal-fired power plants are the only ones capable of producing and supplying electricity in national energy system, regardless of atmospheric conditions - frost, severe drought, absence of wind for wind energy production, when there is not enough sun for normal production of photovoltaic energy or during periods of technical overhaul at nuclear power plants. All this combined with existence of indigenous resources that can be exploited, we believe that the use of coal adds value to the entire supply chain in transition to clean energy. This leads to positive results in terms of both economic performance and short-term employment. Under these conditions and due to the reserves of coal and lignite available in Romania, experience and long tradition of mining, energy consumption can be covered by a mixture 
of fuels where coal will be a component. At the same time, coal-fired extraction and energy production technologies will have to comply with EU rules.

\section{References}

1. European Commission, Energy [Online] Available: https://ec.europa.eu/energy/en [Accessed 18 April 2021]

2. https://ec.europa.eu/energy/sites/ener/files/documents/ro_final_necp_main_ro.pdf_[Accessed 18 April 2021]

3. M.S. Nan, A. Sultan, D. Grecea, C. Vitan, MATEC Web of Conferences 290 (2019)

4. A. Sultan, M.S. Nan, et al., MATEC Web of Conferences 305 (2020)

5. Master-plan privind alimentarea cu energie termica a consumatorilor din Municipiul Motru, (Motru, 2018)

6. N. Diaconu, M.S. Nan, O. Stoicuta, et al, Industria Textila, 70, 1 (2019)

7. MATLAB-Simulink Software User Guide [Online]. Available: https://www.mathworks.com/products/simulink.html [Accessed 18 April 2021]

8. MATLAB-Simulink [Online].

https://www.mathworks.com/help/examples.html [Accessed 18 April 2021]

9. A. Acakpovi, E.B Hagan, F.X. Fifatin, Int. J Comput. Appl., 108, (18), (2014)

10. E. Donaisky, G.H.C. Oliveira, et al., MATEC Web of Conferences, 35 (2015) 